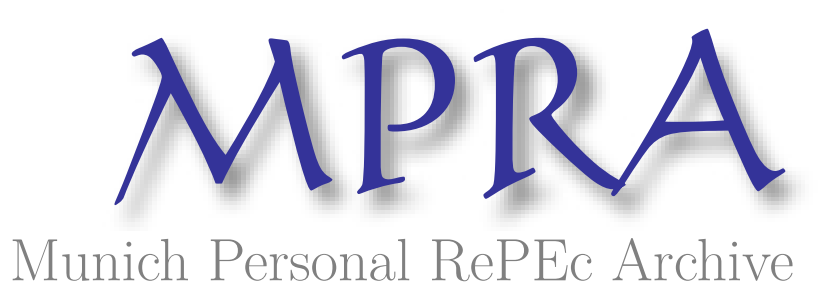

\title{
Indirect Tax Incidence under Inelastic Underground Economy Demand
}

Soldatos, Gerasimos

2014

Online at https://mpra.ub.uni-muenchen.de/64598/

MPRA Paper No. 64598, posted 27 May 2015 06:02 UTC 


\title{
Indirect Tax Incidence under Inelastic Underground Economy Demand
}

\author{
Gerasimos T. SOLDATOS, American University of Athens, 15232 Athens, Greece, \\ soldgera@yahoo.com
}

Published in: Journal of Economics and Behavioral Studies, forthcoming 2015, 7(3)

\begin{abstract}
This paper demonstrates theoretically that a profit tax does not affect the distribution of the firm's operations between the official and the underground economy. Or, if the firm was initially operating only officially, direct taxation of its business would not be a reason to go underground. Indirect taxation in the form of a sales tax does influence an already existing mix of official and underground activities, favoring the latter. And, it does constitute a reason to "go underground" for an otherwise fully official business. This is a thesis robust to market structure changes and to introducing tax evasion in the usual sense, provided the underground demand is inelastic. The tax authority can still collect the planned tax revenue through a combination of a cash-flow tax with indirect taxation, under only consumer-surplus loss by the underground customer.
\end{abstract}

Keywords: Inelastic underground demand, Business-tax shift, Tax policy

\section{Introduction}

The literature on the underground economy is vast (see e.g. Aureo \& Scheinkman, 2008 and Charmes, 2012). And, the literature on tax evasion is equally large; (see e.g. the Fall 2014 symposium on "Tax Enforcement and Compliance" in the Journal of Economic Perspectives). But, to this author's knowledge, the possibility that a tax on business may not be evaded just because it may be shifted to the underground customer has certainly slipped attention. Abstracting from cost-of-capital considerations, such should be the case in so far as an indirect tax is concerned. Even if underground economy was inexistent, it would have to be invented to shift indirect taxation on official sales to the underground customer, to cover with it official business tax payments, and escape the indirect tax on the output that is disposed underground.

This has serious welfare implications not so much for the firm as for the consumer. For the firm, if indirect taxation corrects for market power as Dillén (1995) argues, and if the ability to shift this taxation forward increases with market power as Karp \& Perloff, (1989) appear to suggest, the corrective power of indirect taxation decreases. Yet, this decline might be countered under optimal indirect taxation, because it presupposes equalization of the after-tax Lerner indexes, tax rates increasing subsequently with inelasticity as very well Wang (2011) notes, and increasing inelasticity is one factor conferring increasing market power. But, for the consumer the benefit from having the possibility to buy underground is great since what this means in the pricequantity space of the official economy is a leftward shift of the demand curve enough to cancel out the deadweight loss of taxation.

This is an eventuality worth contemplating to the extent underground demand is inelastic as is supposed to be the case a priori since, (i) something that costs for a buyer $x$ monetary units officially, someone buying it underground is willing to pay any fraction $\gamma$ of $x$ even if this fraction doubles and triples with the passage of time, suffices to continue $\gamma$ being less than $x$, and (ii) at the given underground market price, an underground buyer does not change the seller that circumstances dictate to the buyer. Habit formation might be one, for instance, reason explaining this persistence of underground exchange (see e.g. Koehne \& Kuhn, 2015). Another reason could be a network effect, encouraging underground workers to keep purchasing underground commodities (see e.g. Fortin et al., 2000). And, still another reason in combination perhaps with the two previous ones might be chronic unemployment (see e.g. Windebank, 2004).

In what follows, the next section elaborates upon the idea of underground forward indirect-tax shift exhaustively, taking as a benchmark case that of perfect competition in either type of economy. Methodologically, it is actually a quasi-perfectly competitive case: Once the firm can shift production and output sold across economy types, the long-run constant-cost type of 
industry becomes immaterial. And, so does the specific shape of the demand curve given that the customer too, can shift across economy types. Consequently, we do not have a "textbook perfect competition case", and no precise statements can be made about the tax incidence; but recall that the emphasis here is the study of the possibility of shifting indirect taxation onto the underground customer and not the precise shift. Section 3 concludes this exercise by deliberating about the welfare and policy implications of this idea.

\section{Formal Considerations}

Starting from full underground production at long-run perfectly competitive equilibrium, expanding to official production entails costs à la increasing-cost industry. But, starting from "fully official equilibrium", expanding underground is carried out à la decreasing-cost industry. The expansion is prompted presumably by expanding market demand. If the level of demand is given, the shift of production between the formal and the informal sectors is made along a positively sloped curve whose points indicate the sectoral composition of output at various prices in the sector share (horizontal axis) - price (vertical axis) space in which the long-run equilibrium of the official sector is located at the share which is equal to one. And, once the customer too, can shift across economy types, the perfectly competitive firm itself is facing a negatively sloped demand curve, which can exploit it not as a price-maker but only by varying its product across sectors. Measuring the output of both sectors from the origin of the axes in the output-price space, the demand curve is the line connecting the official equilibrium at official price-output, with the underground one at underground price and total, i.e. formal and informal output. These are in sum the considerations surrounding the notion of perfect competition which is appropriate to the study of the topic investigated below as follows:

\subsection{The Basic Argument}

Suppose for a moment that a fraction $m$ of a perfectly competitive firm's product is already channeled into the underground economy in order to avoid excessive regulations and institutional constraints but not for tax evasion purposes. Such an assumption is plausible if one judges from what, for example, Singh et al. (2012) report. Using the superscript " $s$ " in connection with the standard profit maximization under perfect competition, we have that profit:

$$
\Pi^{s}=(1-m)(p-c) Q+m\left(p^{\prime}-c^{\prime}\right) Q
$$

with $p>p^{\prime}$ and $c>c^{\prime}$, where $p$ is the constant price, $c$ is the constant average and marginal cost, $Q$ denotes quantity, and the prime (') connotes the underground economy. Production underground is presumably cheaper than officially while who would buy underground if the price there was not lower than that in the official sector. Setting $d \Pi^{s} / d Q=0$, one obtains that:

$$
p^{s}=c+\frac{m c^{\prime}}{1-m}-\frac{m}{1-m} p^{\prime s}
$$

Marginal cost pricing in the official economy, $p^{s}=c$, implies from (2) such pricing underground too, $p^{\prime s}=c^{\prime}$.

Would the introduction of direct taxation in the official of course economy alter this pricing behavior of this firm, or would such taxation be a motive to go underground for a firm operating only officially? Using index " $\pi$ " for profit maximization with a profit tax, $\tau \epsilon(0,1)$, profits are:

$$
\Pi^{\pi}=(1-m)(1-\tau)(p-c) Q+m\left(p^{\prime}-c^{\prime}\right) Q
$$

From the condition $d \Pi^{\pi} / d Q=0$ :

$$
p^{\pi}=c+\frac{m c^{\prime}}{(1-m)(1-\tau)}-\frac{m}{(1-m)(1-\tau)} p^{\prime \pi}
$$

with $p^{\pi}=c<=>p^{\prime \pi}=c^{\prime}$ and hence, $p^{\pi}=p^{s}$ and $p^{\prime \pi}=p^{\prime s}$ at the $Q^{\prime}$ s maximizing (1). These are the $Q^{\prime}$ s maximizing (3) too, because $p^{\pi}>c<=>p^{\prime \pi}<c^{\prime}$ and $p^{\pi}<c<=>p^{\prime \pi}>c^{\prime}$. This is a replication of the well-known result that assuming away cost-of-capital considerations, a profit tax does not affect decision-making, since the same pricing derives from the "s-problem", too. 
The profit tax rate may be positive but fully borne by the firm and does not affect the distribution of the firm's operations between the official and the underground economy. Or, if the firm was initially operating only officially, direct taxation of its business would not be a reason to go underground.

Let us ask the same question for the case of indirect taxation. Using index " $a$ " for profit maximization with an ad valorem tax, $t \in(0,1)$ :

$$
\Pi^{a}=(1-m)[(1-t) p-c] Q+m\left(p^{\prime}-c^{\prime}\right) Q
$$

The first order condition gives that

$$
p^{a}=p^{s} /(1-t)
$$

At the optimal $Q$ 's of the "s-problem", $p^{\prime a}=c^{\prime}$ implies that $p^{a}=c /(1-t)>c=>0>-t$, which is true, while $p^{a}=c$ implies that $p^{\prime a}=c^{\prime}+[t(1-m) c / m]>c^{\prime}=>t(1-m) c>0$, which is also true. It follows that if the demand underground is inelastic, it will pay to keep official behavior unaltered and shift the tax to the underground customer by raising underground price given the quantity sold there. Or, if the firm was operating only officially before the indirect tax, it would be advantageous to start operating underground as well: The avoidance of indirect taxation is a reason to go underground provided that underground demand is inelastic.

These results are illustrated through Figure 1 where the price relationships $\left(p, p^{\prime}\right)$ are given by lines $O Z=[c /(1-t)]+\left\{m c^{\prime} /[(1-m)(1-t)]\right\}>O \Gamma=c+\left\{m c^{\prime} /[(1-m)(1-\tau)]\right\}>O A=$ $c+\left[m c^{\prime} /(1-m)\right]$ and where the trigonometric tangents of $\omega, w$, and $v$ are $m /(1-m), m /[(1-m)(1-t)]$, and $m /[(1-m)(1-\tau)]$, respectively. For simplicity, $t=\tau$ has been postulated so that $Z H$ can be parallel to $\Gamma \Delta$. For simplicity too, underground demand, $D^{u}$, has been assumed to be fully inelastic for the individual seller, and $S^{u}$ and $S^{f}$ are the underground and the official market supply, with the superscripts " $u$ " and " $f$ " denoting presumably the underground and the official economy, respectively. With regard to the inelasticity of $D^{u}$, it should be repeated that there is no a priori reason why should an underground buyer change the underground seller with whom the buyer deals at the given underground market price and so long as this price is lower than the official one. Moreover, the percentage corresponding to $m$ is hypothesized to be less than 50 percent so that $m /(1-m)<$ 1 . Line $A B$ is the case before any tax, with optimal price combination $\left(p^{s}, p^{s}\right)$ at point $\Lambda$. A profit only tax would be associated with a line like $\Gamma \Delta$, cutting $A B$ from above at $\Lambda$, leaving unchanged this price combination. And, a sales only tax is illustrated via $\mathrm{ZH}$.

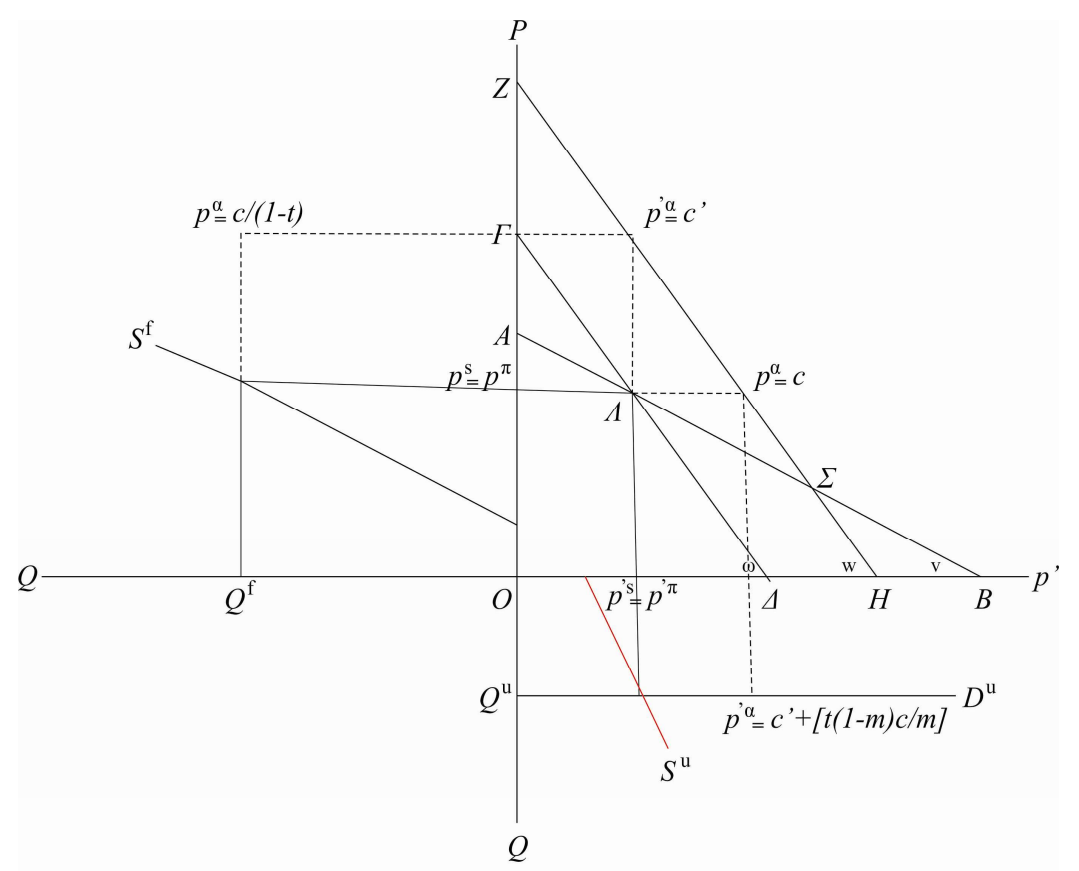

Figure 1: Underground Economy and Taxation 
What should the policymaker do to restore the tax revenue which is presumably pre-determined in line with optimum societal welfare? The answer is to levy a profit tax yielding revenue equal to mtpQ beyond the revenue (1-m)tpQ from the ad valorem tax. The profit tax would not alter $p^{a}$ : From the maximization of:

$$
\Pi^{a \pi}=(1-m)(1-\tau)[(1-t) p-c] Q+m\left(p^{\prime}-c^{\prime}\right) Q
$$

relation (6) is reproduced in the form:

$$
p^{a \pi}=p^{\pi} /(1-t)
$$

Diagrammatically, the new price line would cut $Z H$ from above at point $\Sigma$. Part $(1-m) t p Q$ of tax payment is shifted by the firm to the underground customer and part $m t p Q$ is borne by the firm. As the concluding section below notes, the proposed tax scheme does entail welfare losses especially on the part of the underground customer, and the policymaker cannot avoid the emergence of underground operations. But, the tax authority can certainly collect the planned tax revenue, which supposedly has been budgeted having taken into account this welfare loss.

\subsection{The Issues of Imperfect Competition and Tax Evasion}

Would our conclusions so far be modified under profit maximization with perfect competition in the official economy but Cournot competition in the underground economy? After all, not all firms decide to go underground. This only is assumed here to be the difference among firms. And, subsequently, quantity competition is plausible to contemplate, too. Denote profit in this case by superscript " $\kappa s$ ":

$$
\Pi^{\kappa s}=(1-m)(p-c) Q+m\left[(e-b Q-b \bar{Q})-c^{\prime}\right] Q
$$

where $p^{\prime}=e-b Q-b \bar{Q}$, with $\bar{Q}$ being the output of underground rivals, and with $e$ and $b$ being some constants. From the condition that:

$$
\frac{d \Pi^{\kappa s}}{d Q}=(1-m)(p-c)+m\left(p^{\prime}-c^{\prime}\right)-m b(Q+\bar{Q})=0
$$

and from the condition that at the optimum:

$$
Q+\bar{Q}=\frac{N\left(e-c^{\prime}\right)}{(N+1) b}
$$

one obtains that:

$$
p^{\kappa s}=c+\frac{m c^{\prime}}{1-m}+\frac{m N\left(e-c^{\prime}\right)}{(1-m)(N+1)}-\frac{m}{1-m} p^{\prime \kappa s}
$$

where $N$ is the number of firms that go underground. Marginal cost pricing in the official economy, $p^{\kappa s}=c$, would imply that $p^{\prime \kappa s}=\left(c^{\prime}+N e\right) /(N+1)$, which exceeds $c^{\prime}$ given that $e>c^{\prime}$.

Under a profit tax and profits indexed now by " $\kappa \pi$ ":

$$
\Pi^{\kappa \pi}=(1-m)(1-\tau)(p-c) Q+m\left[(e-b Q-b \bar{Q})-c^{\prime}\right] Q
$$

the relationship between prices becomes:

$$
p^{\kappa \pi}=c+\frac{m c^{\prime}}{(1-m)(1-\tau)}+\frac{m N\left(e-c^{\prime}\right)}{(1-m)(1-\tau)(N+1)}-\frac{m}{(1-m)(1-\tau)} p^{\prime k \pi}
$$

and as before, a profit tax does not affect decision-making, since $p^{\kappa \pi}=c\left(=p^{\kappa s}\right)$ implies that $p^{\prime \kappa \pi}=p^{\prime \kappa s}$.

But, in view of an ad valorem tax: 


$$
\Pi^{\kappa a}=(1-m)[(1-t) p-c] Q+m\left[(e-b Q-b \bar{Q})-c^{\prime}\right] Q
$$

the price relationship becomes:

$$
p^{\kappa a}=p^{\kappa s} /(1-t)
$$

At the optimal $Q$ 's of the " $\kappa s$-problem", $p^{\prime \kappa a}=c^{\prime}$ implies that

$$
p^{\kappa a}=\frac{c}{(1-t)}+\frac{m N\left(e-c^{\prime}\right)}{(1-m)(1-t)(N+1)}
$$

while from $p^{\kappa a}=c$ follows that

$$
p^{\prime \kappa} a=c^{\prime}+\frac{t(1-m) c}{m}+\frac{N\left(e-c^{\prime}\right)}{(N+1)}
$$

The diagrammatical illustration of these results is a scaled-up version of Figure 1, which need not bother us, since the essence of the argument remains the same: The underground economy is an outlet for forward indirect tax shift. It can be easily checked that this would also be true if imperfect competition in the official economy was introduced; the mathematical relationships would only become more complicated. Neither the introduction of tax evasion would alter this argument. Letting $\varphi$ be the probability of detection, (3) becomes:

$$
\Pi^{\varepsilon \pi}=\varphi(1-m)(1-\tau)(p-c) Q+(1-\varphi)(1-m)(p-c) Q+m\left(p^{\prime}-c^{\prime}\right) Q
$$

with

$$
p^{\varepsilon \pi}=c+\frac{m c^{\prime}}{(1-m)(1-\varphi \tau)}-\frac{m}{(1-m)(1-\varphi \tau)} p^{\prime \varepsilon \pi}
$$

while (5) becomes:

$$
\Pi^{\varepsilon a}=\varphi(1-m)[(1-t) p-c] Q+(1-\varphi)(1-m)(p-c) Q+m\left(p^{\prime}-c^{\prime}\right) Q
$$

with

$$
p^{\varepsilon a}=\frac{c}{1-\varphi t}+\frac{m c^{\prime}}{(1-m)(1-\varphi t)}-\frac{m}{(1-m)(1-\varphi t)} p^{\prime \varepsilon a}
$$

where the letter " $\varepsilon$ " in the superscript designates the tax evasion case. Comparing (14) and (16) with (4) and (6), the only change is that $\tau$ and $t$ are now multiplied by $\varphi$. In the presence of both taxes, $\Pi^{a \pi}$ above becomes

$$
\Pi^{\varepsilon a \pi 1}=\varphi(1-m)(1-\tau)[(1-t) p-c] Q+(1-\varphi)(1-m)[(1-t) p-c] Q+m\left(p^{\prime}-c^{\prime}\right) Q
$$

with

$$
p^{\varepsilon a \pi 1}=\frac{c}{1-t}+\frac{m c^{\prime}}{(1-m)(1-t)(1-\varphi \tau)}-\frac{m}{(1-m)(1-t)(1-\varphi \tau)} p^{\varepsilon a \pi 11}
$$

when tax evasion refers only to the profit tax, and

$\Pi^{\varepsilon a \pi 2}=\varphi(1-m)(1-\tau)[(1-t) p-c] Q+(1-\varphi)(1-m)(1-\tau)(p-c) Q+m\left(p^{\prime}-c^{\prime}\right) Q$

with

$$
p^{\varepsilon a \pi 2}=\frac{c}{1-\varphi t}+\frac{m c^{\prime}}{(1-m)(1-\tau)(1-\varphi t)}-\frac{m}{(1-m)(1-\tau)(1-\varphi t)} p^{\prime \varepsilon a \pi 2}
$$

when the case is that of indirect tax evasion. Clearly, $p^{\varepsilon a \pi 1}=p^{\varepsilon \pi} /(1-t)$ and $p^{\varepsilon a \pi 2}=$ $p^{\varepsilon a} /(1-\tau)$. And, in the presence of Cournot competition underground, (13) becomes 


$$
\Pi^{\varepsilon \kappa \pi}=q(1-m)(1-\tau)(p-c) Q+(1-q)(1-m)(p-c) Q+m\left[(e-b Q-b \bar{Q})-c^{\prime}\right] Q
$$

with

$$
p^{\varepsilon \kappa \pi}=c+\frac{m c^{\prime}}{(1-m)(1-\varphi \tau)}+\frac{m N\left(e-c^{\prime}\right)}{(1-m)(1-\varphi \tau)(N+1)}-\frac{m}{(1-m)(1-\varphi \tau)} p^{\prime \varepsilon \kappa \pi}
$$

while (15) becomes

$$
\Pi^{\varepsilon \kappa a}=q(1-m)[(1-t) p-c] Q+(1-q)(1-m)(p-c) Q+m\left[(e-b Q-b \bar{Q})-c^{\prime}\right] Q
$$

with

$$
p^{\varepsilon \kappa a}=\frac{c}{1-\varphi t}+\frac{m c^{\prime}}{(1-m)(1-\varphi t)}+\frac{m N\left(e-c^{\prime}\right)}{(1-m)(1-\varphi t)(N+1)}-\frac{m}{(1-m)(1-\varphi t)} p^{\prime \kappa \kappa a}
$$

Relations $p^{\varepsilon \kappa \pi}$ and $p^{\varepsilon \kappa a}$ are (14) and (16), respectively, incorporating the impact of the ratio: $m N\left(e-c^{\prime}\right) /(N+1)$. Would different detection probabilities for the two taxes, $\varphi$ for the direct tax, and $\psi$ for the indirect tax, alter the picture? Profits for the basic case are now:

$$
\begin{aligned}
\Pi^{\eta a \pi}=\varphi(1-m) & (1-\tau)[(1-t) p-c] Q+(1-\varphi)(1-m)[(1-t) p-c] Q \\
& +\psi(1-m)(1-\tau)[(1-t) p-c] Q+(1-\psi)(1-m)(1-\tau)(p-c) \\
& +m\left(p^{\prime}-c^{\prime}\right) Q
\end{aligned}
$$

with

$$
p^{\eta a \pi}=\frac{[(1-\varphi \tau)+(1-\tau)] c}{\theta}+\frac{m c^{\prime}}{(1-m) \vartheta}-\frac{m}{(1-m) \theta} p^{\prime \eta a \pi}
$$

where $\theta=[(1-t)(1-\varphi \tau)+(1-\tau)(1-\psi t)]$, and the answer to the last question is certainly negative.

\subsection{Empirical Considerations}

To sum up, a positive correlation coefficient between underground economy and indirect tax incidence estimates would be echo empirically the general conclusion from these considerations. Of course, calculating this coefficient or engaging in more detailed empirical work based on these estimates would turn out to be quite a perplexed task. For one thing, the estimates should be not only by consumption type but also for those types whose underground demand is taken somehow to be price inelastic. If not anything else, underground economy statistics are provided as percentages of gross domestic product (GDP), and so should tax incidence estimates be, but such an approach would assume away the issue of underground demand elasticity. And, even if so was actually assumed, the standard approach to estimate tax incidence has to calculate from consumer price index and aggregate tax rate on consumption, consumption, and output data the quantities involved in a formula like the following one:

$$
I=\frac{p-p_{\xi}}{t}+\frac{p_{\xi}-p_{\zeta}}{t p}
$$

where $I$ is the aggregate tax incidence index, while $p, p_{\xi}$, and $p_{\zeta}$, are the recorded consumer price index, the consumer price index estimated in the absence of taxes, and the consumer price index derived somehow at perfectly competitive equilibrium in the absence of taxes too, correspondingly (see e.g. Karp \& Perloff 1989). "Heroic" assumptions have to be made to derive such an $I$, before finally is expressed as a percentage of the GDP. Such a task lies certainly outside the scope of this paper.

Moreover, the formula above raises the issue of the role of market power in the official economy, because it contains two terms acknowledging thus that the real world is not a perfectly competitive one: To assume so has been found to underestimate the incidence, and the second term on the right of the formula corrects for this underestimation. It implies that increased market power increases the ability to shift a tax in line with theoretical arguments like that by 
Peitz \& Reisinger (2009). But, again, is this true if as Konrad et al. (2014, 173), for instance, argue: "Relative to perfect competition, a monopolist bears a large share of the burden of a tax increase... as buyers constrain the pricing behavior of a monopolist"? We saw that this paper does support the former viewpoint. To continue the present paper searching for the conditions that would refute this viewpoint, construct a tax incidence index accordingly, and undertake an empirical work under again the aforementioned "heroic" assumptions accompanying it, comprises a different rather research agenda. It is enough for us here to have established the intuitive result that there is a positive correlation between underground economy and indirect tax incidence.

\section{Concluding Remarks}

Indeed, it follows from the above algebra that the underground economy is clearly an outlet of relief from indirect taxation. And, it appears that this is a state of affairs not to be worrying a government with a tax authority tying indirect taxation with corporate income taxation as outlined earlier. This, too, is a conclusion with much intuitive appeal. Practically the proposed tax combination presupposes a rough only knowledge of $m$ by sector. More important matter is the welfare implications of this combination. It entails loss of consumer surplus beyond the intrinsic regressiveness of a sales tax and especially so with regard to the underground customer whose demand is inelastic and who by no means can be identified with a white-collar worker. Even more so when optimal indirect taxation presupposes equalization of the after-tax Lerner indexes of all commodities and hence, higher tax rates for commodities that have low price elasticities of demand or supply provided that the marginal disutility of labor is constant (see e.g. Wang, 2011).

At the other end, we know from Harberger (1964) that when all commodities are taxable, the Harberger triangles tend to overestimate the welfare loss caused by indirect taxation; much more so when relief is found in the underground economy, we should add in this paper. So, the proposed tax combination is expected to be more or less neutral with regard to the overall consumer welfare; much more so if underground economy is assumed to be maintaining full the overall employment, implying inelastic labor supply and hence, a uniform tax rate on all goods at the optimum. Of course, the complexity of the real world prevents taxation from being designed optimally, and what should be sought as a second best is a well-designed, Pareto improving indirect tax structure.

Ideally, a government should be weighing the costs and benefits of any policy scheme and hence, of the proposed one too, before implementing it in practice. This translates to confining losses to those in consumer surplus, which are inescapable given the conditions of inelasticity surrounding underground demand. Towards this end, the profit tax may take the form of cashflow tax as outlined by the relevant literature (see e.g. Edwards, 2003 and Kanniainen \& Panteghini, 2013). In addition, indirect taxation may be structured so as to alleviate distortions from imperfect competition à la Guesnerie \& Laffont (1978), Dillén (1995), and others who consider efficiency-restoring indirect taxation when firms engage in Bertrand-Nash games. Such indirect taxation would compensate for the welfare loss associated with the inelasticity of underground demand.

The combination of a cash-flow tax with indirect taxation countering market power is an eventuality worth considering empirically too, because as, for instance, Gillis \& Kannekens (2014) report, there is an overwhelming expansion of indirect taxation, which Bernardi (2013) among others fears that will exacerbate the economic slump at least in so far as European Union is concerned. If both Bernardi and the thesis herein are correct, the slump will be about the official economy but will be countered by the underground consumer and producer. For example, Doerrenberg \& Duncan (2014:Abstract) "find that access to evasion opportunities reduces the effective tax rate and therefore dampens real behavioral responses [and] that the benefits of tax evasion are not limited to the side of the market with access to evasion but are partly shifted to the non-evading side of the market". It is a finding readily extendable to include the underground economy in general, countering, for example, Torregrosa's (1999) conclusion that indirect taxation under imperfect competition reduces the balanced budget multiplier. Capital and labor will do move underground in response e.g. to fiscal consolidation, leaving the "overall" multiplier unchanged, or perhaps, increasing it. 
The problem with the tax and the overall fiscal policy is that it is made within the partial equilibrium context of official only economy and may be frustrated by the general equilibrium workings deriving from the presence of an underground sector as well. The same applies to monetary policy. If, for example, as Schmitt-Grohé \& Uribe (2003:Abstract) maintain, "the nominal interest rate acts as an indirect tax on monopoly profits [and] the social planner [does not have] access to a direct 100 percent tax on profits, he will always find it optimal to deviate from the Friedman rule by setting a positive ... nominal interest rate", the tax will pass on to the consumer, encouraging underground economy. Another example is that increased money supply to stimulate consumption will make easier the shift the indirect tax because underground transactions are carried through mostly on cash and the increased cash will make them easier: What will be stimulated is underground rather than official consumption.

\section{References}

Aureo, P. \& Scheinkman, J. (2008). The informal sector, Penn Institute for Economic Research Working Paper 08-018. [Available at / http://economics.sas.upenn.edu/sites/economics.sas. upenn.edu/files/working-papers/08-018.pdf]

Bernardi, L. (2013). Recent findings regarding the shift from direct to indirect taxation within the EA-17, Società Italiana di Economia Pubblica Working Paper 663. [Available at http://www.siepweb.it/siep/images/joomd/1401050783663.pdf]

Charmes, J. (2012). The informal economy worldwide: Trends and characteristics. Margin: The Journal of Applied Economic Research, 6(2), 103-132.

Dillén, M. (1995). Corrective tax and subsidy policies in economics with Bertrand competition. Journal of Public Economics, 58(2), 267-282.

Doerrenberg, P. \& Duncan, D. (2014). Tax incidence in the presence of tax evasion, Institute for the Study of Labor (IZA) Discussion Paper No 8137. [Available at http://ftp.iza.org/dp8137.pdf]

Edwards, C. (2013). Replacing the corporate income tax with a cash-flow tax. Cato Journal, 23(2), 291-318.

Fortin, B., Lacroix, G. \& Montmarquette, C. (2000). Are underground workers more likely to be underground consumers? Economic Journal, 110, 466, 838-860.

Gillis, T. \& Kannekens, W. (2014). Corporate and indirect tax rate survey 2014, KPMG International Cooperative, Switzerland. [Available at http://www.kpmg.com/Global/en/ IssuesAndInsights/ArticlesPublications/Documents/corporate-indirect-tax-rate-survey2014.pdf]

Guesnerie, R. \& Laffont, J.-J. (1978). Taxing price makers. Journal of Economic Theory, 19(2), 423455.

Harberger, A. (1964). Taxation, resource allocation, and welfare, in The Role of Direct And Indirect Taxes in the Federal Revenue System, Princeton, NJ: Princeton University Press.

Kanniainen, V. \& Panteghini, P.M. (2013). Tax neutrality: Illusion or reality? The case of entrepreneurship. FinanzArchiv: Public Finance Analysis, 69(2), 167-193.

Karp, L.S. \& Perloff, J.M. (1989). Estimating market structure and tax incidence: The Japanese television market. Journal of Industrial Economics, 37(3), 225-239.

Koehne, S. \& Kuhn, M. (2015). Optimal taxation in a habit formation economy. Journal of Public Economics, 122, 32-39.

Konrad, K.A., Morath, F. \& Müller, W. (2014). Taxation and market power. Canadian Journal of Economics / Revue canadienne d'Economique, 47(1), 173-202. 
Peitz, M. \& Reisinger, M. (2009). Indirect taxation in vertical oligopoly, SFB/TR 15 Discussion Paper No. 255. [Available at http://epub.ub.uni-muenchen.de/13297/1/255.pdf]

Schmitt-Grohé, S. \& Uribe, M. (2003). Optimal fiscal and monetary policy under imperfect competition, NBER Working Papers No 10149. [Available at http://www.nber.org/papers/ w10149.pdf]

Singh, A., Jain-Chandra, S. \& Mohommad, A. (2012). Inclusive growth, institutions, and the underground economy, IMF Working Paper 12/47. [Available at https://www.imf.org/external /pubs/ft/wp/2012/wp1247.pdf]

Torregrosa, R., (1999). Balanced budget multiplier, imperfect competition and indirect taxation, Instituto Valenciano de Investigaciones Económicas, S.A. (IVIE) Working Papers Series EC No. 2. [Available at http://www.ivie.es/downloads/docs/wpasec/wpasec-1999-02.pdf]

Wang, H., (2011). Optimal indirect taxation under imperfect competition, Peking University, China Center for Economic Research Working Paper No E2010016. [Available at http://hwang.ccer.edu.cn/Tax\%20201105.pdf]

Windebank, J., (2004). Demand-side incentives to combat the underground economy: Some lessons from France and Belgium. International Journal of Economic Development, 6(2), 54-75.

\section{Acknowledgements}

I am grateful to two anonymous reviewers for useful comments and suggestions. Any remaining errors or omissions are my own. 